\title{
New approaches to the study of Antarctic lithobiontic microorganisms and their inorganic traces, and their application in the detection of life in Martian rocks
}

Received: 8 March 2002 / Accepted: 15 April 2002 / Published online: 27 August 2002

(C) Springer-Verlag and SEM 2002

\begin{abstract}
Microbial life in the harsh conditions of Antarctica's cold desert may be considered an analogue of potential life on early Mars. In order to explore the development and survival of this epilithic and endolithic form of microbial life, our most sophisticated, state-ofthe-art visualization technologies have to be used to their full potential. The study of any ecosystem requires a knowledge of its components and the processes that take place within it. If we are to understand the structure and function of each component of the microecosystems that inhabit lithic substrates, we need to be able to quantify and identify the microorganisms present in each lithobiontic ecological niche and to accurately characterize the mineralogical features of these hidden microhabitats. Once we have established the techniques that will allow us to observe and identify these microorganisms and mineral substrates in situ, and have confirmed the presence of water, the following questions can be addressed: How are the microorganisms organized in the fissures or cavities? Which microorganisms are present and how many are there? Additional questions that logically follow include: What are the existing water relationships in the microhabitat and what effects do the microorganisms have on the mineral composition? Mechanical and chemical changes in minerals and mineralization of microbial cells can give rise to physical and/or chemical traces (biomarkers) and to microbial fossil formation. In this report, we describe the detection of chains of magnetite within the Martian meteorite ALH84001, as an example of the potential use of SEM-
\end{abstract}

C. Ascaso $(\square)$

Centro de Ciencias Medioambientales CSIC,

c/ Serrano 115 bis, 28006 Madrid, Spain

E-mail: ascaso@ccma.csic.es

Tel.: + 34-917452500

Fax: + 34-915640800

J. Wierzchos

Servei de Microscòpia Electrònica,

Universitat de Lleida, Av. Rovira Roure 44,

25198 Lleida, Spain
BSE in the search for plausible traces of life on early Mars.

Keywords ALH84001 - Antarctica .

Biomarkers · Cryptoendoliths · Lithobionts · Ross

Desert $\cdot$ Microbial fossils

\section{Background}

The term biocomplexity has recently been used with reference to the study of an ecosystem at the highest level. The analysis of an ecosystem or a microecosystem, which is performed at a scale of hundreds of cubic microns, requires knowledge of its components and their dynamic interrelations. The great scientific interest in exploring the ecology of Antarctic, lithobiontic microorganisms may be attributed to the fact that they are the only known form of life able to withstand the conditions of this extremely cold and dry macro- and micro-environment of our planet.

Microbial ecology studies in the Dry Valley area of the Ross Desert (Antarctica) commenced in 1976, when E. I. Friedmann and R. Ocampo reported their observation of cyanobacteria (i.e. Gloecapsa) within the Beacon sandstone [10]. This demonstration of the presence of indigenous microbiota colonizing the inside of Antarctic desert rocks was a landmark eventin extreme environment microbial ecology. Since then, several species of endolithic cyanobacteria, fungi and protolichens have been described [see review in 25]. Scientific interest in these lithobiontic microorganisms may be ascribed to several reasons. First, the Antarctic Dry Valley desert zone represents the most hostile lithic environment for the survival of living organisms on Earth. Under the extreme low-temperature conditions of some areas of the Ross Desert (mean annual temperature $-25^{\circ} \mathrm{C}$ ), the metabolic activity of endolithic microorganisms can only be sustained for a couple of days per year $[11,12]$. However, although scarce, the occasional presence of liquid water in this ecological system is the primary 
condition for the existence of life in Antarctica [15]. When the delicate balance of biological, geological and/ or climatic factors is upset and microbial life decays, the presence of microbial fossils [27] and/or biomarkers [28] can indisputably indicate the previous existence of life. The ability to recognize these fossils and the biomarkers left behind may have important astrobiological implications. It has been suggested that the endolithic microbial ecosystems of the Antarctic desert are the closest terrestrial models of the last stages of life on early Mars [16]. Indeed, the microbial ecology of these lithobiontic, extremophile microorganism communities could provide clues to answering the challenging question of how life (if ever present) became extinct on Mars. In the near future, the scientific community will be given the opportunity to search for traces of past microbial activity in carefully selected samples from the Martian regolith. It is therefore extremely important that we improve our knowledge of the microbial ecology of Antarctic desert endolithic communities, so that we are able to confidently identify live microorganisms and their traces. According to Conrad and Nealson [5], when we can easily recognize life in Earth's environments, we will be prepared to move beyond the confines of our planet.

\section{How should we approach the study of Antarctic lithobiontic microorganisms?}

Given the complexity of cold desert ecosystems, and considering that microbial ecology involves the study of the relationships that microorganisms have with their natural environment, these investigations need to be performed in the natural lithobiontic microhabitat. T. D. Brock [4], who defined microbial ecology as the study of microorganisms in their natural environment, proposed that the investigator should work on microorganisms in situ. Our interpretation of this is that the epilithic or endolithic microhabitat must not be disturbed. The study of microorganisms adhered to or found inside a rock presents enormous difficulties. Nevertheless, the biological and mineralogical components of the microhabitat in each lithobiontic ecological niche [14] need to be precisely characterized in order to understand the range of dynamic relationships among them. If the microorganism-substrate interface is examined using appropriate in situ observation techniques, we should be able to morphologically characterize the biological elements present and also observe their ultrastructure. It should also be possible to characterize at the morphological and structural levels - minerals close to the microorganisms, to give us some idea of how the interface functions. In lithic substrates, the study of each lithobiontic ecological niche requires the ability to quantify and identify the microorganisms present and to characterize the mineralogical features of the microhabitat in order to understand the structure and function of the microecosystem. This may be achieved using a series of new techniques of in situ observation of microorganisms and mineral substrates. Based on our experience in the in situ study of lithobiontic microorganisms [e.g. 25], we strongly recommend the following microscopy (and microanalysis) techniques: scanning electron microscopy with back-scattered electron imaging (SEM-BSE) combined with an energydispersive X-ray spectroscopy (EDS) microanalytical system, low-temperature SEM (LTSEM) and confocal laser scanning microscopy (CLSM).

Scanning electron microscopy with back-scattered electron imaging combined with a microanalytical system

The SEM-BSE method consists of two steps. The first is sample preparation, which involves fixing the rock fragments in glutaraldehyde, staining with osmium tetraoxide and/or uranyl acetate, and preparing finely polished blocks containing the samples embedded in resin [22]. In the second step, a transverse section of the carbon-coated biological-mineralogical sample is observed using the BSE detector. The BSE signal is strongly dependent on the mean atomic number of the target. Thus, the SEM-BSE technique not only permits visualization of samples with different inorganic features but also allows heavy-metal-stained ultrastructural elements to be identified in the biological material. Coupling of an EDS facility to the SEM-BSE instrument permits the chemical characterization (qualitative and quantitative determination of elements and elemental spatial distribution images) of mineral features [23,24]. Figure 1a, b, Fig. 2a-g, and Fig. 3a-d are SEM-BSE images of lithobionts and their mineral substrates in Antarctic rocks.

\section{Confocal laser scanning microscopy}

The ability to clearly visualize endoliths using CLSM suggests its suitability for in situ microbial ecology studies of such difficult habitats. Community structure and relationships between their components may also be examined using "live-dead" microbial stains and fluorescent probes. Figure 1d shows a CLSM image of a cryptoendolithic protolichen from Antarctic sandstone. Moreover, information on the spatial distribution of the microorganism's cells may also allow an estimate of the number of microorganisms occupying a particular pore volume in any type of rock or environment. In the future, it may also be possible to combine CLSM with fluorescent in situ hybridization (FISH) to identify different groups of microorganisms inside the rock. So far, the direct PCR-amplification of the internal transcribe spacer (ITS) regions of rDNA from an endolithic fungi has been achieved and the results compared with that of the mycobiont of the closest epilithic lichen thallus (A De los Rios, C. Ascaso, H. Grube, Mycological Research. 106, 2002. In Press). 
Fig. 1a-d Endolithic microorganisms in Antarctic rocks. a SEM-BSE image of a cryptoendolithic protolichen within the fissure of granite rock from maritime Antarctica. Arrows algae, open arrow hyphal cells. b SEM-BSE detailed view of a cryptoendolithic lichen photobiont (granite). $A$ Algae, $H$ hyphal cells, $c h$ chloroplast, $p y$ pyrenoid zone, $c w$ cell walls. c LTSEM image showing tufts of ice crystals. $W$ Indicative of the presence of water, $H$ hyphal cells. d CLSM image of a 3Dreconstructed cryptoendolithic protolichen colonizing a deep pore space between quartz grains (stars) in Antarctic sandstone rocks. $A$ Photobiont cells, $H$ mycobiont cells

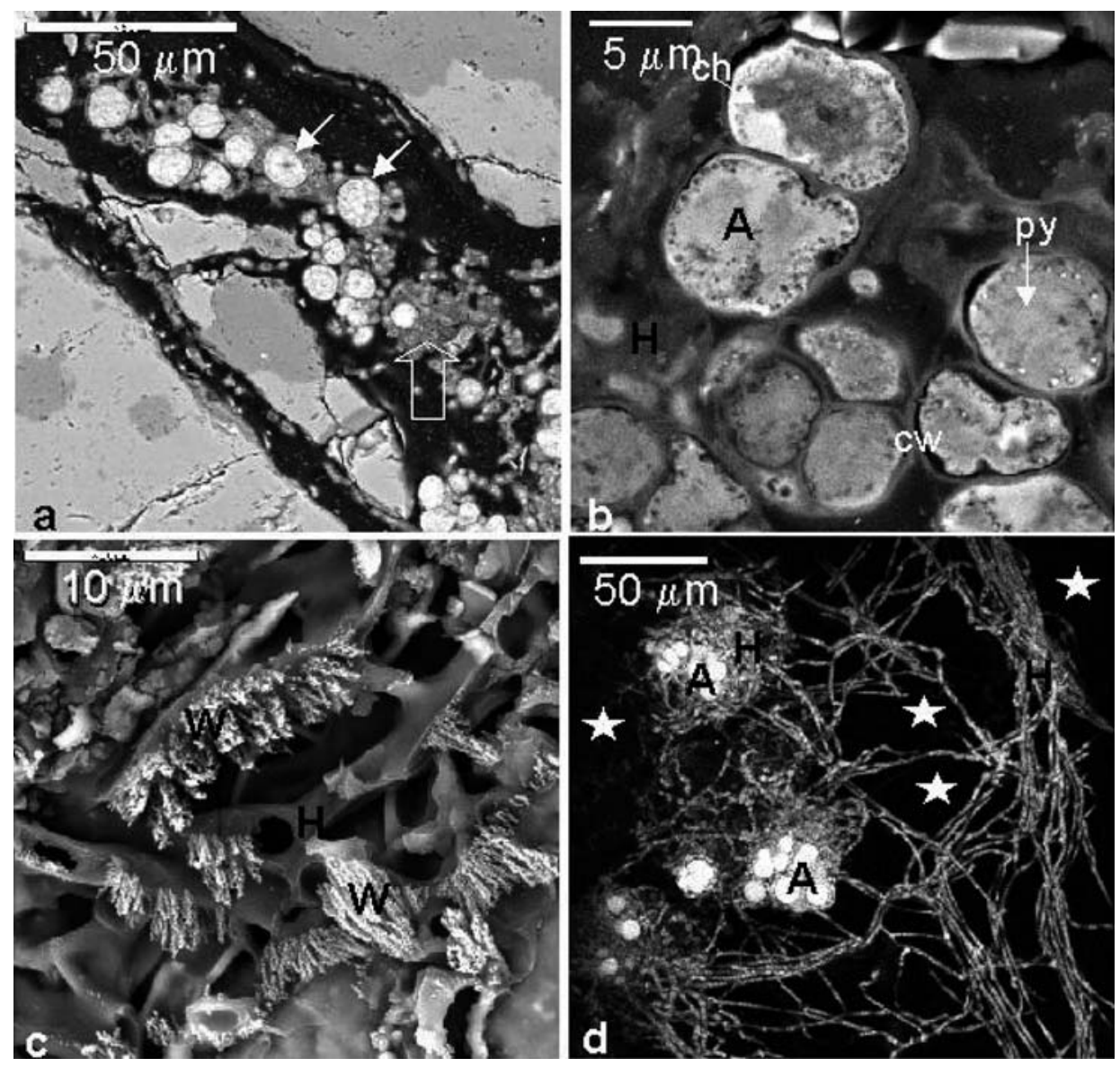

Low-temperature scanning electron microscopy

The traditionally used method of room temperature SEM in secondary electron (SE) detection mode gives rise to topographical images of the rock interior but yields only an external morphological description of the endolithic cells. This morphology provided by SEM-SE, working under high vacuum or with environmental SEM performed at normal atmospheric pressure, generally fails to provide the investigator with sufficient information to be able to discern the different microorganisms found in a pore or fissure. Furthermore, working at room temperature or under vacuum it is not possible to see the microhabitat's water or ice, which is a very important component if we are to understand the ecological processes that take place.

The use of LTSEM offers several advantages for the in situ investigation of endoliths in rock samples from the Ross Desert. LTSEM techniques permit the preservation of whole specimens in a close-to-natural state, since samples are ultra-rapidly cryofixed, causing the quick and complete immobilization of cells in their original state. Some of the cryofixed cells may also be randomly cut to reveal ultrastructural elements. LTSEM also enables the user to observe the polymeric matrix structure (EPS) in a hydrated state. Moreover, the hydration stage and/or presence of water (ice) in both biological and inorganic components can be determined.

\section{Which features of the ecology of lithobiontic microorganisms can be explored?}

\section{Organization of microorganisms in fissures or cavities}

Once we have the adequate techniques, the first question posed might be related to the organization and location of endoliths within cracks, fissures and pores. Using the SEM-BSE and CLSM, we were able to confirm the presence of a narrow biotic band 1-2 $\mathrm{mm}$ below the rock surface in sandstone (orthoquartzite) from the Ross Desert. This zone is mostly occupied by cryptoendolithic protolichens (see CLSM image in Fig. 1d). These protolichens have a different internal organization compared to the usual epilithic thalloid lichen. Their mycobiontic hyphae show lax growth inside the rock pores. A lack of coherent plectenchyma was also noted. The hyphae act as bridges for glomeruli formed by algae and hyphae via the spaces among quartz grains. CLSM does not allow the quartz grains to be visualized, but their position has been marked in Fig. 1d with stars. The spatial relationship among different organisms established by this technique can help us begin to understand the interrelations between microorganisms. Their position in the pore/fissure microhabitat will be associated with their fluorescence ability. In narrow fissures and cracks in granite from maritime Antarctica, microor- 
Fig. 2a-g SEM-BSE images of inorganic biogenetic deposits biomarkers and lithobiontic communities in Antarctic rocks. a Diagenetic Fe-oxyhydroxide and aluminosilicate deposits (arrows) around live hyphal cells $(H)$. b EDS spatial distribution of $\mathrm{Fe}$ corresponding to a. c Live endolithic bacterial colony (open arrow) and associated diagenetic Fe-rich deposits-inorganic collapsed bacterial biomarkers (bright structures). d Diagenetic Fe-oxyhydroxide and aluminosilicate deposits (arrows) around a live cyanobacterial colony $(C B) . m$ Bioweathered biotite sheets. e Diagenetic aluminosilicate clay (asterisk) and Fe-oxyhydroxide ( $\mathrm{Fe}-\mathrm{ox}$ ) biomarkers around decaying hyphal cells (black arrows). $H$ Live hyphae cells, open arrow live bacterial colony. f Calcium oxalate deposits (oxa) around live fungi $(H)$ and their crusts. g Silica biogenetic deposit with holes (asterisks) in close proximity to bacteria (open arrow)
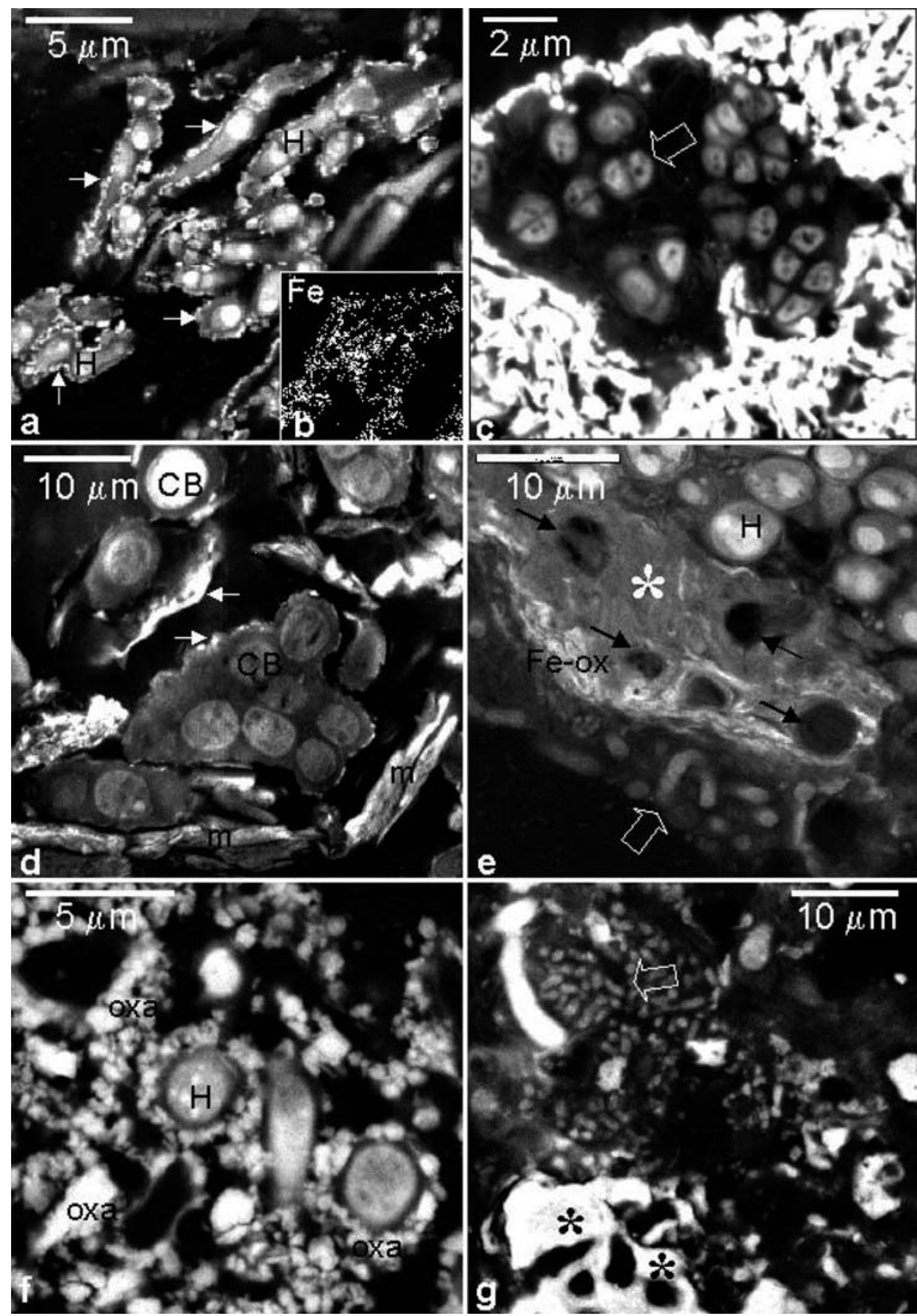

ganisms were detected at a depth of up to $5 \mathrm{~mm}$ (SEM-BSE image in Fig. 1a).

Establishing the number of microorganisms per unit microhabitat volume

Crustose, endolithic lichens and protolichens, and endolithic microorganisms have been rarely investigated by ecophysiological methods, due precisely to their intricate connection with the substratum. Some studies in which gas exchange was determined have provided approximations of the biomass of Antarctic endolithic microorganisms. Confocal microscopy allows microorganisms to be visualized inside fissures in three dimensional form and so their number can be estimated. The CLSM option of estimating the number of microorganisms per unit volume of the pore or fissure and knowing whether a microorganism shows photosynthetic capacity, such as algae or cyanobacteria, allows a much more precise interpretation of gas exchange data obtained in situ on the surface of Antarctic rocks. 
Fig. 3 a SEM-BSE image of fossilized cryptoendolithic protolichen cells within Antarctic sandstone rock from $\mathrm{Mt}$. Fleming. $A$ algae, $H$ hyphae. Mineralized ultrastructural elements: $c w$ cell walls, $c h$ chloroplast membrane, py pyrenoid zone within the fully-mineralized algal cells. Long white arrow EDS microprobe scanline profile; asterisks cw zone. b EDS scan-line of relative concentrations of $\mathrm{Al}, \mathrm{Si}, \mathrm{K}$ and $\mathrm{Fe}$ along the white arrow in a. Asterisks Cell wall zone rich in Fe. c, d SEM-BSE image of fossilized cells (sandstone from Mt. Fleming) of unidentified microorganisms showing the presence of a mineralized cell wall structure $(\mathrm{cw})$

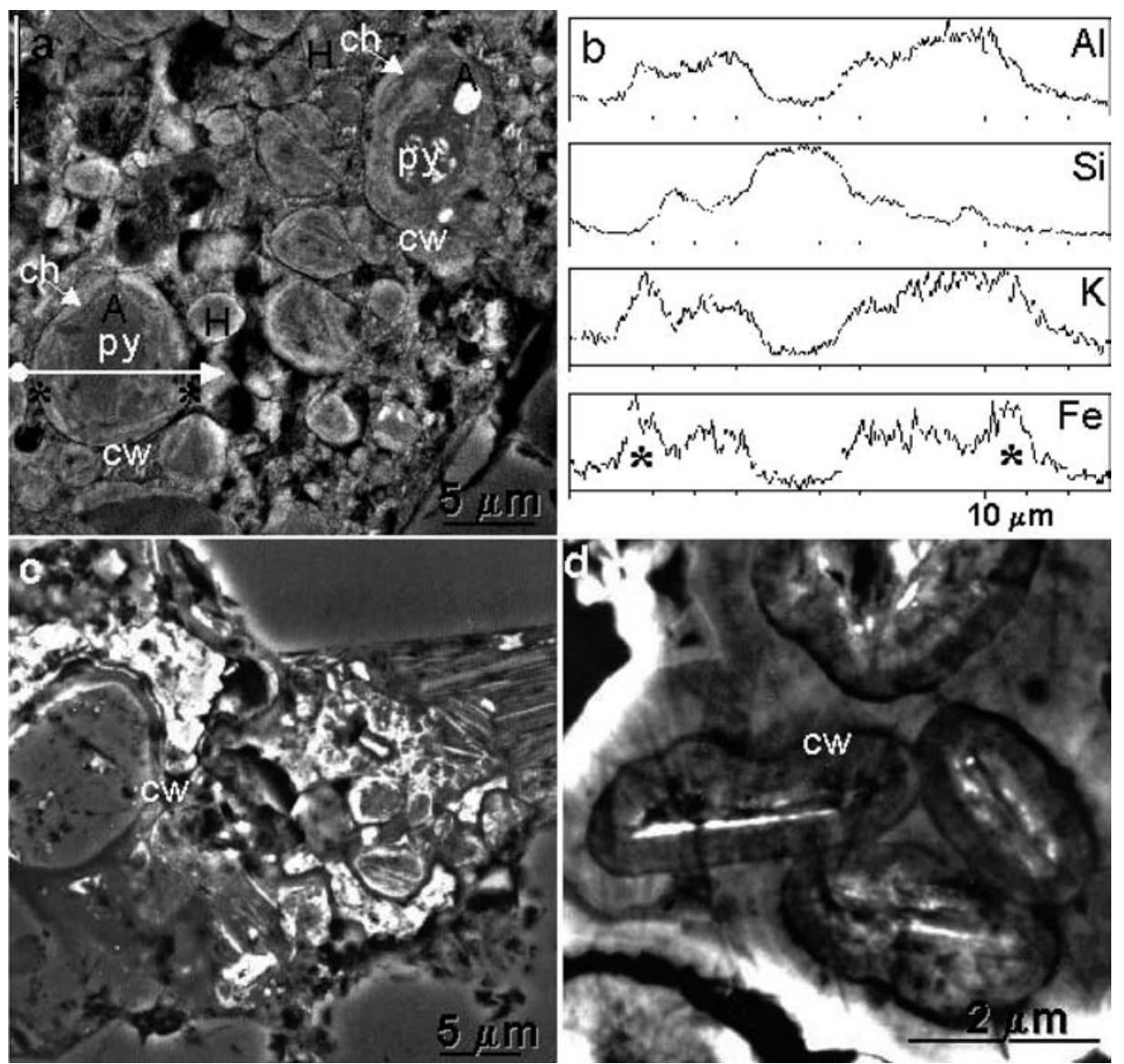

Gaining knowledge on the structural characteristics of biotic and abiotic components and identifying the former

This is very important question from the point of view of microbial ecology. It is highly probable that most Antarctic endoliths cannot be successfully cultured under laboratory conditions. This means they are viable but not culturable. Thus, the only possibility is in situ study of the microorganisms and their morphological and ultrastructural characteristics through SEM-BSE. However, this strategy can only be applied when the different cell structures can be recognized, since only when we become familiar with something are we able to subsequently recognize it. A lithic biofilm is formed by prokaryotic and eukaryotic microorganisms in close proximity with minerals and extracellular polymeric substances. SEM-BSE has proved to be of great use in determining which type of microorganisms and minerals comprise the lithic biofilm. Its use in situ enables the presence of cryptoendolithic protolichens (Fig. 1a) to be demonstrated. These protolichens consist of photobiont cells (Fig. 1a, white arrows) with characteristic ultrastructural elements, such as lipid bodies, chloroplasts and pyrenoid zones (shown in Fig. 1b), and hyphae (open arrow in Fig. 1a). Cyanobacteria are the predominant microorganisms in these cryptoendolithic communities (SEM-BSE images in Fig. 2d). Other ecological niches are colonized by fungi (Figs. 2a, e, f) and endolithic bacteria (open arrows in Figs. 2c, e, g). The CLSM technique serves to identify different groups of microorganisms by FISH. The use of a specific fluorescent riboprobe, which hybridizes in situ to the rRNA of a particular microorganism, might permit the identification and localization of different microorganisms within their substrate. Characterizing microorganisms and mineral structures by SEM-BSE combined with CLSM-FISH identification of the microorganisms could allow all the components of a microhabitat to be recognized and the processes going on within it (i.e., its biocomplexity) to be understood.

\section{Localizing water in the microhabitat's components}

Over the past few years, LTSEM has proved to be a valuable technique for the evaluation of structural changes occurring in epilithic lichen thalli of different water contents [e.g., 6]. LTSEM enables the ultrastructure of hydrated frozen microorganisms, and the EPS in the frozen hydrated state to be observed, and also localizes water (ice) in microorganisms and near-by minerals. Rock moisture is generally too low for the activation of endolithic photosynthetic microorganisms, 
but small amounts of water have been detected in the hyphae of "dehydrated" protolichens. Figure 1c show an LTSEM image of cryptoendolithic hyphae. The bright "tufts" in the image correspond to zones where ice crystals formed after sample fracturing, indicating the previous presence of liquid water or ice, probably in the apoplastic channels of the fungal cells.

Relationships between microorganisms and their environment (i.e., surrounding minerals)

Mechanical and chemical changes in bioweathered minerals can leave behind physical and/or chemical signs (biomarkers). These traces of past microbial activity are best explored using SEM-BSE combined with an EDS microanalytical system. Physicochemical changes in biotite caused by microbial activity at the microorganism-substrate interface of Antarctic rocks have been recently reported [26]. The biophysical weathering of biotite gives rise to exfoliation and ondulation of biotite sheets as a result of microbial growth between these sheets and moisture-dependent expansion and contraction processes, as well as those produced by freezing-thawing. The SEM-BSE image in Fig. $2 d$ shows bioweathered layers of micaceous mineral close to endolithic cyanobacteria in Antarctic sandstone. Biochemical alteration of biotite in Antarctic rocks leads to potassium depletion from the biotite layers in zones of direct contact between hyphae and mica sheets [26]. Microorganisms act as sinks for potassium and promote biotite weathering [2]. Biotite biochemical weathering leading to potassium depletion and thus its transformation to vermiculite interstratified biotite has been reported [23,24].

\section{Biomarkers of microbial activity in Antarctic rocks}

Physicochemical bioweathering patterns of minerals, if well established, may be considered inorganic biomarkers. The term "biomarker" refers to the traces left by living microorganisms due to their biological activity. We recently demonstrated that some of the minerals in Antarctic rocks are biologically transformed, and, as a result, Fe-rich biogenic minerals in the form of iron oxyhydroxide nanocrystals and biogenic clays are deposited around chasmoendolithic hyphae and bacterial cells [28]. Owing to their ability to immobilize cations, it has been previously demonstrated that fungi and bacteria may act as nucleating agents for $\mathrm{Fe}$-oxyhydroxide and aluminosilicate, and give rise to fine-grained minerals $[7,8,9,19,21]$.

The SEM-BSE images presented herein show iron oxyhydroxide deposits around live endolithic Antarctic hyphal (Fig. 2a), bacterial (Fig. 2c) and cyanobacterial (Fig. 2d) cells. In other cases, the bioweathering of micaceous minerals leads to the formation of diagenetic
Fe-rich aluminosilicates (asterisk in Fig. 2e). When endoliths decay, the presence of $\mathrm{Fe}$-oxyhydroxide deposits and Fe-rich diagenetic minerals can be interpreted as biomarkers, either because they contain remnants of ultrastructural cell elements or because it is possible to demonstrate the transition from deposits around live cells to deposits with no apparent cellular remains [28] Calcium oxalate crystals are another example of biomarkers of microbial biochemical activity found around endolithic hyphae from Antarctic granite (Fig. 2f). This biomineral arises from the oxalic acid produced by fungal hyphae. Even when hyphal cells have decayed, the surrounding oxalate crystals preserve the characteristic morphology of the deposits, with oxalates forming crust around the empty holes. In some epilithic lichen thalli colonizing Antarctic granite, large deposits composed of silica with characteristic holes have been observed by SEM-BSE (asterisks in Fig. 2g). This rock also contains colonies of bacterial cells (arrow in Fig. 2g). It may not be inferred whether bacteria were originally responsible for the formation of these silica deposits, yet their characteristic morphology and the proximity of bacteria and hyphae (the latter are not shown in Fig. $2 \mathrm{~g}$ ) indicate these deposits are an example of an inorganic biomarker.

\section{Microbial fossils in Antarctic rocks}

The search for microbial fossils is more revealing when efforts are centered on detecting microbial activity rather than on defining what is or is not the biomarker. Microbial fossil formation may take place when extensive biomobilization of elements occurs during biological activity, as well after the decay of microbes. Recent application of SEM-BSE (EDS) has allowed us to demonstrate the presence of microbial fossils within Antarctic sandstone rocks collected from the Ross Desert for the first time $[1,25,27,28]$. We consider this technique an ideal tool for the detection, description, and characterization of microbial fossils, since the in situ study of inorganic biomorphs sometimes allows internal cell structures within fossilized cells to be recognized. Indeed, we propose this feature as a new criterion for establishing the biogenicity of biomorphs. Experience and previous knowledge of internal cell structures gained by SEM-BSE and transmission electron microscopy techniques are required. Here we present examples of fossilized microbial cells found within sandstone rocks. The SEM-BSE image in Fig. 3a shows a group of fossilized algal and hyphal cells. Note that ultrastructural elements such as chloroplasts, cell walls, and pyrenoid zones could be distinguished. Microanalytical (EDS scan-line) determination of the chemical composition of a fossilized algal cell (Fig. 3b), indicates Si accumulation in the center of the fossilized cell and higher $\mathrm{Al}, \mathrm{K}$, and $\mathrm{Fe}$ concentrations in the chloroplast zone. The EDS scan-line shows the presence of iron mostly in the fossilized cell walls (asterisks in Figs. 3a, b). In some 
images of fossilized microbes, only the cell wall can be clearly distinguished (SEM-BSE images in Figs. 3c, d). However, based on the criteria for biogenicity described elsewhere [18,27], we consider these structures to be microbial fossils.

\section{Characterizing plausible biomarkers in Martian meteorite ALH84001}

Fine-grained magnetite has been observed in the Fe-rich rims around carbonate globules in Martian meteorite ALH84001 [17,20]. The authors suggested that these magnetite crystals were similar to those formed by terrestrial magnetotactic bacteria and may therefore be the fossil remains of Martian organisms. Based on radioactive isotopic characteristics of $\mathrm{Mg}$-Fe-Ca-rich carbonate globules, it has been demonstrated that these carbonates were formed $3.9 \pm 0.04 \times 10^{9}$ years ago, a time when there was water on the surface of Mars [3]. Accordingly, there is no doubt as to the Martian origin of these magnetite crystals embedded within the carbonate globules [13].

Terrestrial magnetotactic bacteria produce well-ordered, intracellular magnetite crystals (magnetosomes shown in the SEM-BSE image in Fig. 4a) characterized by specific properties that include: restriction of particle size and shape to the single-domain field, lack of internal defects, presence of unique magnetite crystal morphologies, and arrangement of magnetosomes as characteristic linear chains [20]. Magnetotaxis in bacteria leading to the formation of such magnetosomes is a very special biological adaptation to the Earth's magnetic field. To date, no inorganic process is known to give rise to structures such as these magnetite chains.

The most significant observation we reported [13] was the presence of numerous chains composed of up to 15 magnetite crystals in Martian meteorite ALH84001. Observation of these chains was possible only through the application of SEM-BSE. Back-scattered electrons provide an extremely useful signal related to composi- tion, local specimen surface inclination, crystallography, and internal magnetic field. The back-scattered electrons are not only emitted from the sample surface but also from within the depths of the electron affected target. Figure $4 \mathrm{~b}$ shows a cluster of magnetite crystals from a small carbonate grain embedded in orthopyroxene. Within this mixture of crystals, a chain of eight magnetite crystals was observed (arrow in Fig. 4b). The SEM-BSE image in Fig. 4c shows different examples of magnetite-composed chains observed within the Fe-MgCa-rich carbonate matrix. To rule out any possible doubts concerning the composition of these Fe-rich chain-forming grains, we used an Auger electron spectroscopy (AES) nanoprobe and an EDS microanalytical system. This allowed chemical identification of the chain structures as iron oxides. Five characteristics of magnetite chains (uniform crystal size and shape within chains, gaps between crystals, orientation of elongated crystals along the chain axis, flexibility of chains, and a halo that is possibly a remnant of a membrane around chains), observed or inferred to be present in magnetotactic bacteria yet incompatible with a nonbiological origin, were shown. We can safely rule out any potential terrestrial contamination and/or preparation artifacts based on: (1) the Martian origin of the carbonate globules, (2) several carbonate grains containing magnetite chains were enclosed in plagioclase glass from Mars, (3) the interior of small ALH84001 chips kept in uranyl acetate solution under vacuum remained free of uranyl contamination in the Fe-rich zones, and (4) chains were also detected by SEM-BSE in the untreated freshly fractured Martian rock samples. In terrestrial sediments, these chains are considered indisputable biomarkers of the previous presence of bacteria in the material that gave rise to the sediments. However, we cannot preclude the possibility of chemical reactions occurring on Mars that are unknown on our planet. Through an inorganic process, these reactions may have yielded the chains of magnetite in ALH84001 discovered by us.

According to the hypothesis described in [13], we propose the following tentative scenario to explain the
Fig. 4 a SEM-BSE image of a magnetosome chain in a freeze-dried culture of Magnetospirillum magnetotacticum. b SEM-BSE micrograph of a chain of eight elongated magnetite particles aligned along their long axes found within the Martian meteorite ALH84001 (arrow). c Magnetite composed chains (arrows) observed within the $\mathrm{Fe}-\mathrm{Mg}$-Ca-rich carbonate matrix $(c a)$ of the ALH84001 meteorite
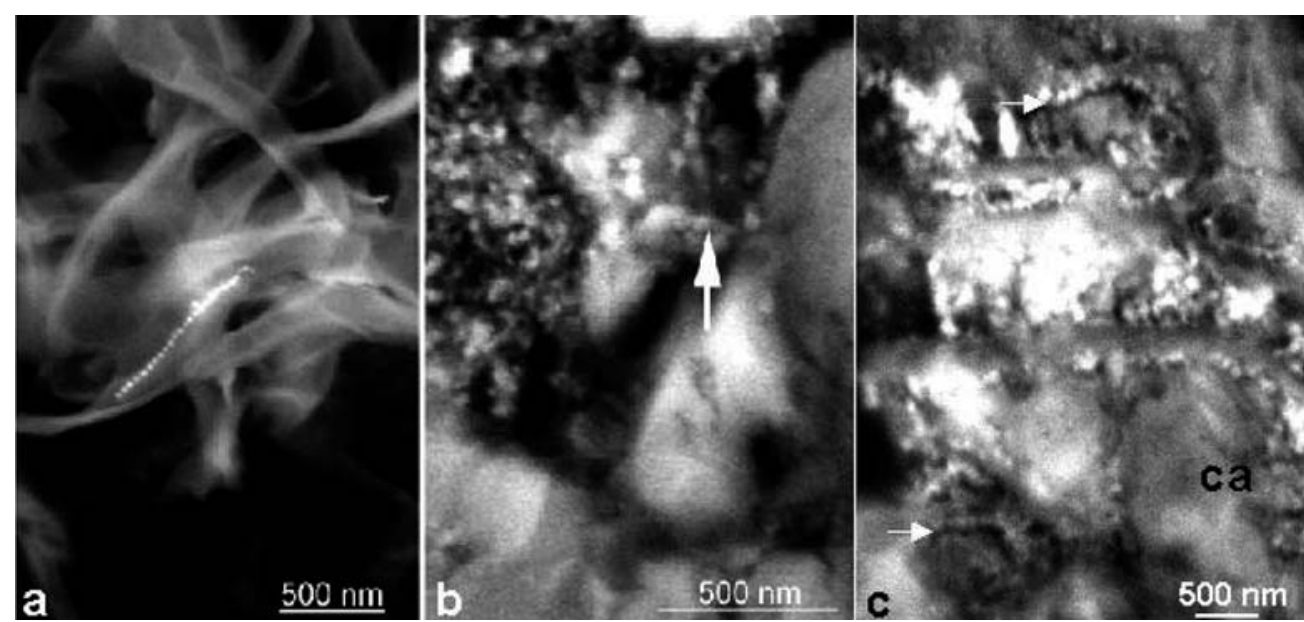
presence of magnetite chains in meteorite ALH84001: decomposed remains of dead magnetotactic bacteria, possibly suspended in a carbonate-rich fluid, penetrated the fissures of ALH84001, and single magnetite crystals and chain fragments were deposited in the carbonate globules.

\section{Conclusions}

There is an obvious need for extensive further work on live lithobiontic Antarctic microorganisms, their inorganic biomarkers, and microbial fossil formation. As we continue to learn more about the survival mechanisms used by these microorganisms and the processes that lead to the formation of inorganic remains of live microbial cells, novel procedures for the detection of life are likely to emerge. In our opinion, the in situ examination of the interior of Antarctic rocks using SEMBSE, microanalytical EDS, LTSEM and CLSM might be the best option available to improve our knowledge of these extreme cold and dry microbial habitats. It is foreseen that this type of work will have applications in astrobiological investigations performed on geological material obtained from Mars.

Acknowledgements Thanks are due to Prof. E. I. Friedmann for supplying the Antarctic sandstone rock samples from Mount Fleming, to L.G. Sancho for granite rock samples from Granite Harbour, to A. Burton for the English revision, to R. Rodriguez Ochoa for helpful comments and to F. Pinto for technical assistance. This study was funded by grant number ANT99-0680-C02-02 of the Plan Nacional I+D and BOS2000-1121 from the PGC.

\section{References}

1. Ascaso C (2000) Lichens on rock substrates: observation of biomineralization process. In: Schroeter B, Schlensog M, Green TGA (eds) New aspects in cryptogamic research. Contribution in honour of Ludger Kappen. J. Cremer in der Gebrüder Borntraeger Verlagsbuchhandlung, Berlin-Stuttgart, pp 127135

2. Barker WW, Welch SA, Bannfield JF (1997) Biochemical weathering of silicate minerals. In: Bannfield JF, Nealson KH (eds) Geomicrobiology: Interactions between microbes and minerals. Mineralogical Society of America, Washington, pp 391-428

3. Borg LE, Connelly JN, Nyquist LE, Shih C-Y, Wiesmann H, Reese Y (1999) The age of the carbonates in Martian meteorite ALH84001. Science 286:90-93

4. Brock TD (1987) The study of the microorganisms in situ: progress and problems. In: Fletcher M, Gray TRG, Jones JG (eds) Ecology of microbial communities. Society for General Microbiology, Cambridge, pp 1-17

5. Conrad PG, Nealson KH (2001) A non-Earthcentric approach to life detection. Astrobiology 1:15-24

6. De los Rios A, Ascaso C, Wierzchos J (1999) Study of lichens with different state of hydration by the combination of low temperature scanning electron and confocal laser scanning microscopies. Int Microbiol 2:251-257

7. Fortin D, Ferris FG, Beveridge TJ (1997) Surface-mediated mineral development by bacteria. Rev Mineral 35:161-180
8. Fortin D, Ferris FG (1998) Precipitation of dissolved silica, sulfate and iron on bacterial surfaces. Geomicrobiol J 15:309324

9. Fortin D, Ferris FG, Scott SD (1998) Formation of Fe-silicates and Fe-oxides on bacterial surfaces in samples collected near hydrothermal vents on the Southern Explorer Ridge in the northeast Pacific Ocean. Am Miner 83:1399-1408

10. Friedmann EI, Ocampo R (1976) Endolithic blue-green algae in the Dry Valleys: primary producers in the Antarctic desert ecosystem. Science 193:1247-1249

11. Friedmann EI, Koriem AM (1989) Life on Mars: how it disappeared (if it was ever there). Adv Space Res 9:167-172

12. Friedmann EI, Druk AY, McKay CP (1994) Limits of life and microbial extinction in the Antarctic desert. Antarctic J US 29:176-179

13. Friedmann EI, Wierzchos J, Ascaso C, Winklhofer M (2001) Chains of magnetite crystals in the meteorite ALH84001: evidence of biological origin. Proc Natl Acad Sci USA 98:21762181

14. Golubic SI, Friedmann EI, Schneider J (1981) The lithobiontic ecological niche, with spatial reference to microorganisms. J Sediment Petrol 51:475-478

15. Kennedy AD (1993) Water as limiting factor in the Antarctic terrestrial environment: a biogeographical synthesis. Arctic and Alpine Res 25:308-315

16. McKay CP, Friedmann EI, Wharton RA, Davis WL (1992) History of water on Mars: a biological perspective. Adv Space Res 12:231-238

17. McKay DS, Gibson EK Jr, Thomas-Keprta KL, Vali H, Romanek CS, Clemett SJ, Chillier XDF, Maechling CR, Zare RN (1996) Search for past life on Mars: possible relic biogenic activity in Martian Meteorite ALH84001. Science 273:924-930

18. McKinley JP, Stewens TO, Westall F (2000) Microfossils and paleoenvironments in deep subsurface basalt samples. Geomicrobiol J 17:43-54

19. Nealson KH (1983) The microbial iron cycle. In: Krumbein WE (ed) Microbial geochemistry. Blackwell, Oxford, pp 159170

20. Thomas-Keprta KL, Bazylinski DA, Kirschvink JL, Clement SJ, McKay DS, Wentworth SJ, Vali H, Gibson EK Jr, Romanek CS (2001) Truncated hexa-octahedral magnetite crystals in ALH84001: presumptive biosignatures. Proc Natl Acad Sci USA 98:2164-2169

21. Warren LA, Ferris FG (1998) Continuum between sorption and precipitation of $\mathrm{Fe}(\mathrm{III})$ on bacterial cell surfaces. Environ Sci Technol 32:2331-2337

22. Wierzchos J, Ascaso C (1994) Application of back-scattered electron imaging to the study of the lichen-rock interface. J Microsc 175:54-59

23. Wierzchos J, Ascaso C (1996) Morphological and chemical features of bioweathered granitic biotite induced by lichen activity. Clays Clay Miner 44:652-657

24. Wierzchos J, Ascaso C (1998) Mineralogical transformation of bioweathered granitic biotite studied by HRTEM: evidence for a new pathway in lichen activity. Clays Clay Miner 46:446-452

25. Wierzchos J, Ascaso C (2001) Life, decay and fossilisation of endolithic microorganisms from the Ross Desert, Antarctica: suggestions for in situ further research. Polar Biol 24:863-868

26. Wierzchos J, de los Rios A, Sancho LG, Green A, Ascaso C (2001) Combination of different microscopy techniques for the integrated study of extremophile endolithic microorganisms and their habitats. Proc First Eur Workshop on Exo-Astrobiology, ESA SP-496, pp 405-408

27. Wierzchos J, Ascaso C (2002) Microbial fossil record of rocks from the Ross Desert, Antarctica: implications in the search for past life on Mars. Int J Astrobiology 1:51-59

28. Wierzchos J, Ascaso C, Sancho LG, Green A (2002) Iron-rich diagenetic minerals are biomarkers of microbial activity in Antarctic rocks. Geomicrob J (in press) 